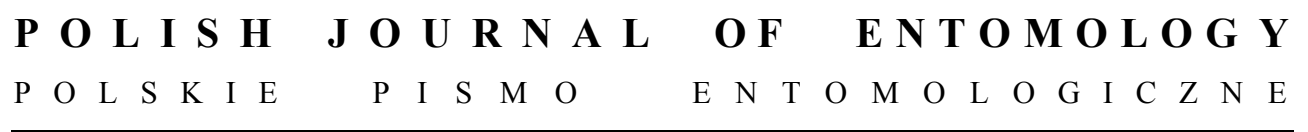

VOL. 82: $365-377$

Gdańsk

31 December 2013

DOI: $10.2478 / \mathrm{v} 10200-012-0050-7$

\title{
Morphology of the first instar larvae of two species of Taxigramma PERRIS, 1852 (Diptera: Sarcophagidae: Miltogramminae)
}

\author{
KRZYSZTOF SZPILA ${ }^{1} \&$ THOMAS PAPE ${ }^{2}$ \\ ${ }^{1}$ Nicolaus Copernicus University, Faculty of Biology and Environmental Protection, \\ Chair of Ecology and Biogeography, Lwowska 1, 87-100 Torun, Poland, \\ e-mail: szpila@umk.pl; \\ ${ }^{2}$ Natural History Museum of Denmark, University of Copenhagen, Universitetsparken 15, \\ 2100 Copenhagen, Denmark, e-mail: TPape@snm.ku.dk
}

\begin{abstract}
The first instar larva is described for two species of the kleptoparasitic miltogrammine genus Taxigramma PERRIS: T. albina (ROHDENDORF) and T. karakulensis (ENDERLEIN). Using a combination of light microscopy and scanning electron microscopy, the following morphological structures are documented: pseudocephalon, antennal complex, maxillary palpus, facial mask, modifications of thoracic and abdominal segments, anal region, spiracular field, posterior spiracles and details of the cephaloskeleton. The first instar larvae of T. albina and T. karakulensis exhibit substantial modification of their morphology by presence of large antennal dome, partial reduction of the antennal basal ring, lack of oral ridges, lack of dorsal bridge, strong modification of spinulation and lack of hair-like spines around the spiracular field. These character states may be treated as apomorphies in comparison with the plesiomorphic ground plan defined for larvae of saprophagous calyptrate flies.
\end{abstract}

KEY WORDS: Sarcophagidae, Miltogramminae, Taxigramma, first instar larva, morphology, SEM.

\section{INTRODUCTION}

In the last ten years much new information has been produced about the larval morphology of the flesh fly subfamily Miltogramminae. The larval stages of 76 species (in 19 genera), especially the first instar, have been described for the first time, or their morphology has been extensively revised (SZPILA 2010, SZPILA \& PAPE 2005a, 2005b, 2007, 2008). 
Currently, Miltogramminae are among the groups of higher Diptera for which we have the most extensive knowledge of the early preimaginal stages. Unfortunately, existing data relate mostly to European species, whereas this taxon is most speciose in the warmer arid and semi-arid areas of the Old World (PAPE 1996). Information about the larval stages of species from outside Europe remains scarce, and the present paper is a step towards remedying this situation.

Based entirely on adult morphology, the current classification of the Miltogramminae needs revising or corroborating through the incorporation of both larval characters and molecular data. The genus Taxigramma PERRIS, 1852 is no exception since, T. pluriseta (PANDELLÉ, 1895) for example, apparently does not belong in this genus because of its strongly deviant first instar morphology (SzPILA 2010). According to the World Catalogue of Sarcophagidae, Taxigramma contains 19 valid species (PAPE 1996). However, it is important to note that in earlier taxonomic publications, Taxigramma (sensu PAPE) had the status of a subtribe and contained at least three separate genera (ROHDENDORF 1967, VERVES 1989). All species of Taxigramma whose biology is known are kleptoparasites in the nests of sphecid, or more rarely, pompilid wasps (PAPE 1987, PovolnÝ \& Verves 1997, SPOFFORD \& KURCZEWSKI 1990, Richet et al. 2013). They have adopted a larviposition strategy described as 'stalkers and lurkers', where females follow a wasp as it transports its prey and larviposit immediately after provision of the nest by the wasp (SPOFFORD \& KURCZEWSKI 1990). Having been deposited at the entrance of the nest, larvae crawl into the nest towards the food supplies accumulated by the wasp. To date, six Taxigramma species have had their first instar morphology described (SZPILA 2010). In all of these cases the larvae display substantial morphological modifications in comparison with the plesiomorphic ground-plan morphology of saprophagous calyptrate flies. The present paper gives data on the first instar larva of two additional species, Taxigramma albina (ROHDENDORF, 1935) and T. karakulensis (ENDERLEIN, 1933). This contribution will assist future taxonomic revisions and evolutionary studies of the genus Taxigramma and indeed the entire subfamily Miltogramminae.

\section{Acknowledgements}

The senior author is grateful to Yoram Ayal (Ben-Gurion University of the Negev, Sede-Boker Campus), Amnon Freidberg (Tel-Aviv University) and Antonius van Harten (UAE Insect Project) for help in organizing excellent collecting trips. The present work was financially supported by the Polish Ministry of Science and Higher Education (project No. 2 P04F 005 29) and the National Science Centre, Poland (project No. 2012/07/B/NZ8/00158). James Wallman (University of Wollongong) kindly checked the language. 


\section{MATERIAL AND METHODS}

Larval material was obtained by keeping wild-caught females under laboratory conditions. Females were collected at localities in Israel and the United Arab Emirates. To obtain larvae, freshly caught females were kept individually in $3 \mathrm{ml}$ Eppendorf tubes with a finely perforated cover. During the following days, females, if gravid, spontaneously and repeatedly larviposited, and the first instar larvae were immediately collected and processed as explained below. After the natural death of a captive female, additional larvae were extracted by gently squeezing her abdomen. All females were subsequently pinned and labelled. They were identified using the key of ROHDENDORF (1935). Larvae were killed by soaking in hot water (about $95^{\circ}$ Celsius) to avoid deformation and stored in $70 \%$ ethanol. Preserved larvae were slide-mounted in Hoyer's medium for light microscopy. Preparation for SEM involved dehydration in 80, 90 and $99.5 \%$ ethanol and critical-point drying in $\mathrm{CO}_{2}$. The larvae were eventually coated with platinum. SEM pictures were taken with a JEOL JSM 6335F field emission microscope. Light microscope illustrations were produced from photographs taken with a digital NIKON 8400 camera mounted on a NIKON ECLIPSE E200 microscope. Drawings were prepared with black ink and subsequently digitalized and finalized in Photoshop ${ }^{\circledR}$.

The females examined have been deposited at the Natural History Museum, University of Copenhagen, Denmark (ZMUC) and the Chair of Ecology and Biogeography, Nicolaus Copernicus University, Toruń, Poland (CEB). All larvae and microscope slides have been deposited at CEB.

The larval terminology follows COURTNEY et al. (2000) with a few modifications proposed by SzPILA \& PAPE (2007) and SzPILA (2010).

\section{RESULTS}

\section{Taxigramma albina (ROHDENDORF, 1935)}

(Figs 1A-G, 2A-F, 4A, B, 5A, B)

\section{Material examined}

11 larvae, larviposited by female: Israel "ISRAEL, Ein Avdat National Park, 15-18.V.2004, Milt4, leg. K. Szpila"; 17 larvae, larviposited by female: Israel "ISRAEL, Ein Avdat National Park, 15-18.V.2004, Milt8, leg. K. Szpila”; 16 larvae, larviposited by female: Israel "ISRAEL, Ein Avdat National Park, 15-18.V.2004, Milt15, leg. K. Szpila”; 10 larvae, larviposited by female: Israel "ISRAEL, Ein Avdat National Park, 21-22.V.2004, Milt32, leg. K. Szpila"; 12 larvae, larviposited by female: Israel "ISRAEL, Ein Avdat National Park, 21-22.V.2004, Milt40, leg. K. Szpila"; 8 larvae, larviposited by female: 
Israel "ISRAEL, Ein Avdat National Park, 25-26.V.2004, Milt61, leg. K. Szpila"; 14 larvae, larviposited by female: United Arab Emirates "UAE, Al Ain, Jebel Hafit, 21.IV.2004, M14, leg. K. Szpila”.

\section{Description}

Pseudocephalon. Antennal complex large, antennal dome (ad) parallel, long and robust with slightly conical tip, ad enlarged in relation to size of basal ring (br) (Fig. 1A, B); maxillary palpus (mp) shaped as flat disc clearly distinguished from surrounding surface of pseudocephalon, first sensillum basiconicum ( $\mathrm{sb} 1$ ) shifted from central cluster of sensilla to inner periphery of mp, tip of sb1 swollen (Fig. 1B, C); ventral organ (vo) on large, flat, fleshy lobe (Fig. 1B, D); pseudocephalon with large papilla (co) laterally with sensillum ampullaceum in centre (Fig. 1G); oral ridges absent; lateral edges of functional mouth opening with several parallel ribs (Fig. 1B, E); anterior surface of pseudocephalon with several cuticular warts between an and $\mathrm{mp}$, posterior surface of pseudocephalon (behind an) with fine cuticular ridges (Fig. 1A, G).

Cephaloskeleton. Labrum (lb) elongated, slightly curved downward, gradually tapering to sharp anterior tip (Figs 4B, 5A); mouthhooks (mh) with very broad basal part, anterior part slender, tip of mh single, sharp and bent downwards almost at right angle (Figs 4B, $5 \mathrm{~A}$ ); intermediate sclerite (isc) adjoins parastomal bars ( $\mathrm{pb}$ ) in lateral view, is longer than broad in ventral view, with transverse junction relatively narrow (Fig. 5B); pb short and thick (Figs 4B, 5A, B); basal sclerite slightly higher than long; vertical plate (vp) very broad, broader than dorsal cornua (dc) and ventral cornua (vc) (Figs 4B, 5A); dorsal bridge absent; elements of cephaloskeleton well sclerotized (Fig. 4B).

Thoracic segments. Anterior spinose band (asb) with from four (lateral surface) to fourteen (ventral surface of first thoracic segment (t1), dorsal surface of second thoracic segment (t2)) rows of spines, spines arranged separately (Fig. 1A, B); dorsal and lateral surfaces of segment t1 behind anterior spinose bands with transverse row of several cylindrical or bulbous papillae (Figs 1A, F; 2A); dorso-lateral surface of segments t2-t3 with horizontal row of spines (dhrs) fused with anterior spinose band, two single bulbous papillae above and below horizontal row of spines (Fig. 1A); lateral papilla with elongated sensillum.

Abdominal segments. Anterior spinose band complete on segments a1-a4 and with two to five rows (dorsal surface) of spines, asb on a5 interrupted on lateral surface, a6 with spines of asb only on ventral surface, all spines arranged separately (Fig. 4A); posterior spinose band (psb) present on segments a1-a6, psb on segments a1-a5 restricted to lateral and ventral surfaces, psb on segment a6 restricted to ventro-lateral and ventral surfaces, several (4-7) conical spines of psb on ventro-lateral surface of segments a1-a6 enlarged and robust (Fig. 2C); lateral creeping welt (lcw) well developed and covered by spines on segments a1-4; ventral creeping welt (vcw) developed (Fig. 1C); segments a1-a7 
with dhrs on dorso-lateral surface, row anteriorly fused with asb and posteriorly with psb, two single bulbous papillae above and below dhrs (Fig. 2B); segments a1-a6 also with horizontal row of spines on ventro-lateral surface (vhrs) (Fig. 2C); remaining surface of segments a1-a7 with fine cuticular ridges (Fig. 2B, C, D); lateral papilla with two sensilla (one elongated) situated in shallow pit; segments a1-a7 with pre-crevice proleg (prl) (Fig. 2C, D).

Anal division. Anterior spinose band on anal division (ad) reduced to ventral surface; dorso-lateral surface of ad with horizontal row of spines; remaining surface of ad with fine cuticular ridges (Fig. 2E, F); papillae p1-p7 clearly visible as fleshy cones with sensillum on top (Fig. 2E, F); two groups of spines on lateral edges of spiracular field, hair-like spines absent (Fig. 2F); transverse groups of small spines directed toward anterior end of body on spiracular field below posterior spiracles (ps), spines arranged in short clusters where spines are fused basally (Fig. 2F); ps with four peristigmatic tufts, distal margin of tufts serrated to form five to eight regular branches (Fig. 2E); anal pads (ap) robust and conical, with long apical sensillum; anal tuft with several small spines (Fig. 2F).

\section{Taxigramma karakulensis (ENDERLEIN, 1933)}

(Figs 3A-H, 4C-E, 5C, D)

\section{Material examined}

14 larvae, larviposited by female: United Arab Emirates "UAE, Tawian (Tawiyeen), 23.IV.2005, M21, leg. K. Szpila".

\section{Description}

Pseudocephalon. Antennal complex large, ad parallel, long and robust with rounded tip, an enlarged in relation to br (Fig. 3A); mp shaped as flat disc clearly distinguished from surrounding surface of pseudocephalon, sb1 elongated and shifted from central cluster of sensilla to inner periphery of mp, tip of sb1 swollen, central cluster of sensilla with large additional sensillum coeloconicum; vo on flat, fleshy lobe; pseudocephalon with two large papillae laterally with sensillum ampullaceum (?) in centre; oral ridges absent; lateral edges of functional mouth opening with several parallel ribs; anterior surface of pc between an and $\mathrm{mp}$ without cuticular warts, posterior surface of pc (behind an) with fine cuticular ridges.

Cephaloskeleton. Labrum elongated, basal part straight, anterior part slightly curved downwards, gradually tapering to sharp tip (Figs 4C, 5C); mh with slightly broader basal part, anterior part slender, tip of mh single, sharp and bent down (Figs 4C, 5C); isc adjoins pb in lateral view (Figs $4 \mathrm{C}, 5 \mathrm{C}$ ), is longer than broad in ventral view, with transverse junction relatively narrow (Fig. 5D); pb long (Figs 4C; 5C, D); basal sclerite slightly higher than long; vp the same width as dc and narrower than width of vc (Figs 4C, 5C); dorsal bridge absent; elements of cephaloskeleton well sclerotized, except mh and distal part of vc (Fig. 4C). 

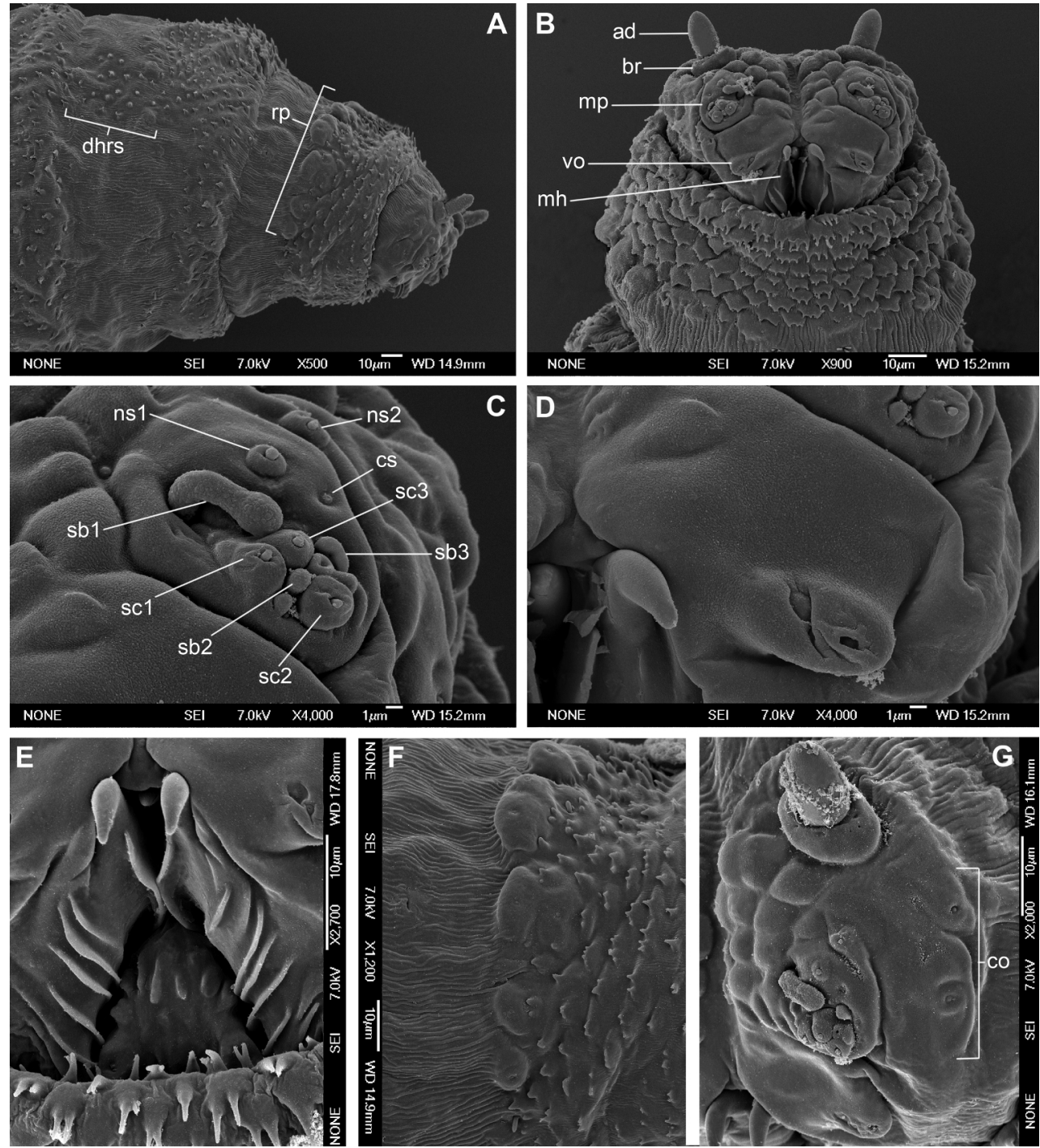

Fig. 1A-G. First instar larva of Taxigramma albina: A - anterior end, lateral view, B - anterior end, ventral view, C - maxillary palpus, D - ventral organ, E - functional mouth opening, $\mathrm{F}$ - t1, lateral view, row of papillae, $\mathrm{G}$ - left lobe of pseudocephalon, anterior view. ad - antennal dome, br - antennal basal ring, co - sensilla on lateral surface of pseudocephalon, cs - sensilla on dorsolateral part of maxillary palpus, dhrs - dorsal horizontal row of spines, $\mathrm{mh}$ - mouthhook, $\mathrm{mp}$ - maxillary palpus, $\mathrm{ns} 1$ - first additional sensillum coeloconicum, $\mathrm{ns} 2$ - second additional sensillum coeloconicum, $\mathrm{rp}$ - transverse row of papillae, sb1-3 - sensilla basiconica 1-3, sc1-3 - sensilla coeloconica 1-3 - vo, ventral organ, $\mathrm{t} 1$ - thoracic segment 1. 

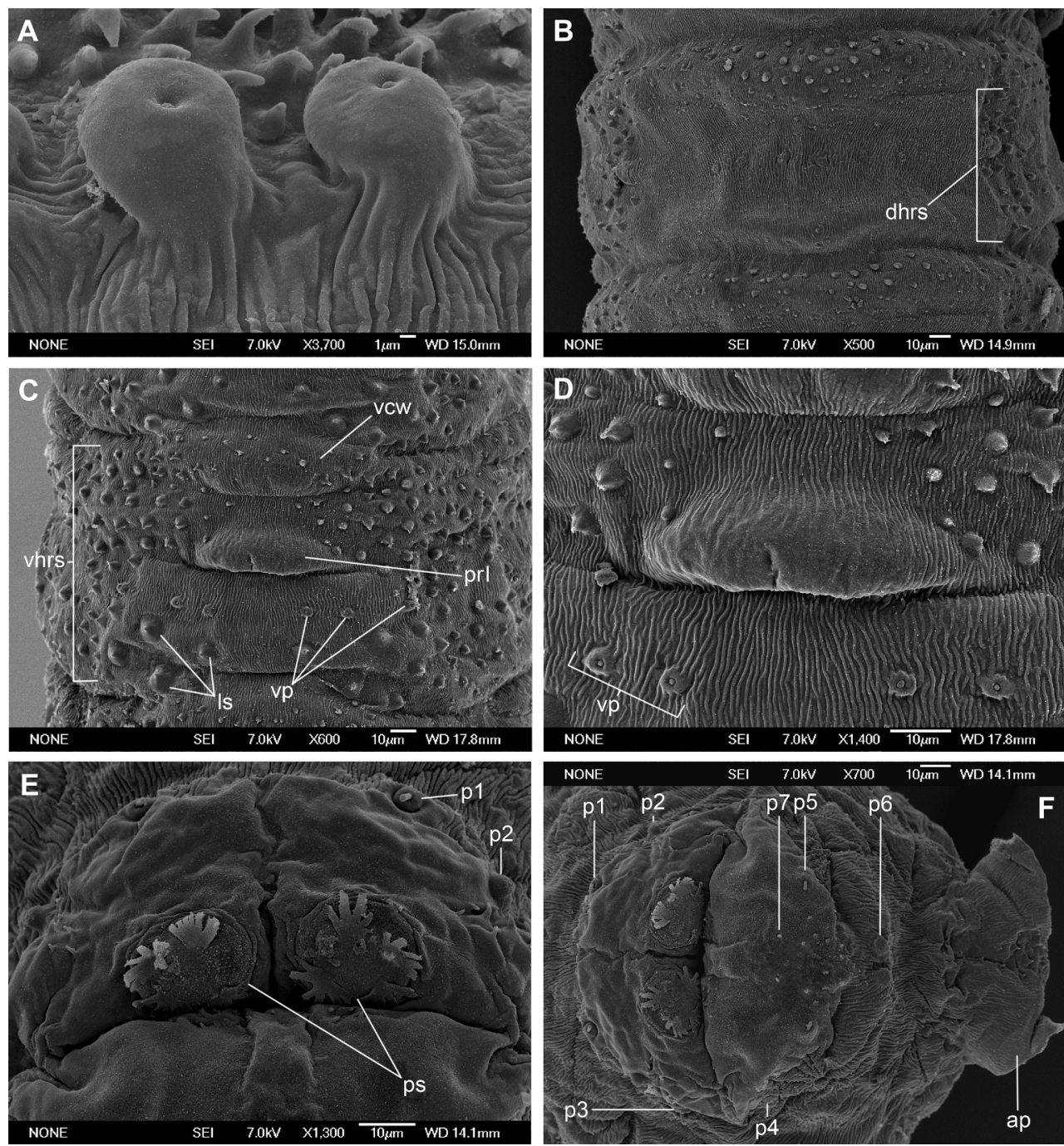

Fig. 2A-F. First instar larva of Taxigramma albina: A - t1, dorsal view, papillae, B - a2, dorsal view, $\mathrm{C}-\mathrm{a} 2$, ventral view, $\mathrm{D}$ - pre-crevice proleg, $\mathrm{E}$ - posterior spiracles, $\mathrm{F}$ - posterior body end, posterior view.

a2 - abdominal segment 2, ap - anal pad, dhrs - dorsal horizontal row of spines, ls - enlarged spines, p1-7 - papillae around spiracular field, prl - pre-crevice proleg, ps - posterior spiracle, $\mathrm{t} 1$ - thoracic segment 1 , vcw - ventral creeping welt, vhrs - ventral horizontal row of spines, vp - ventral papillae. 

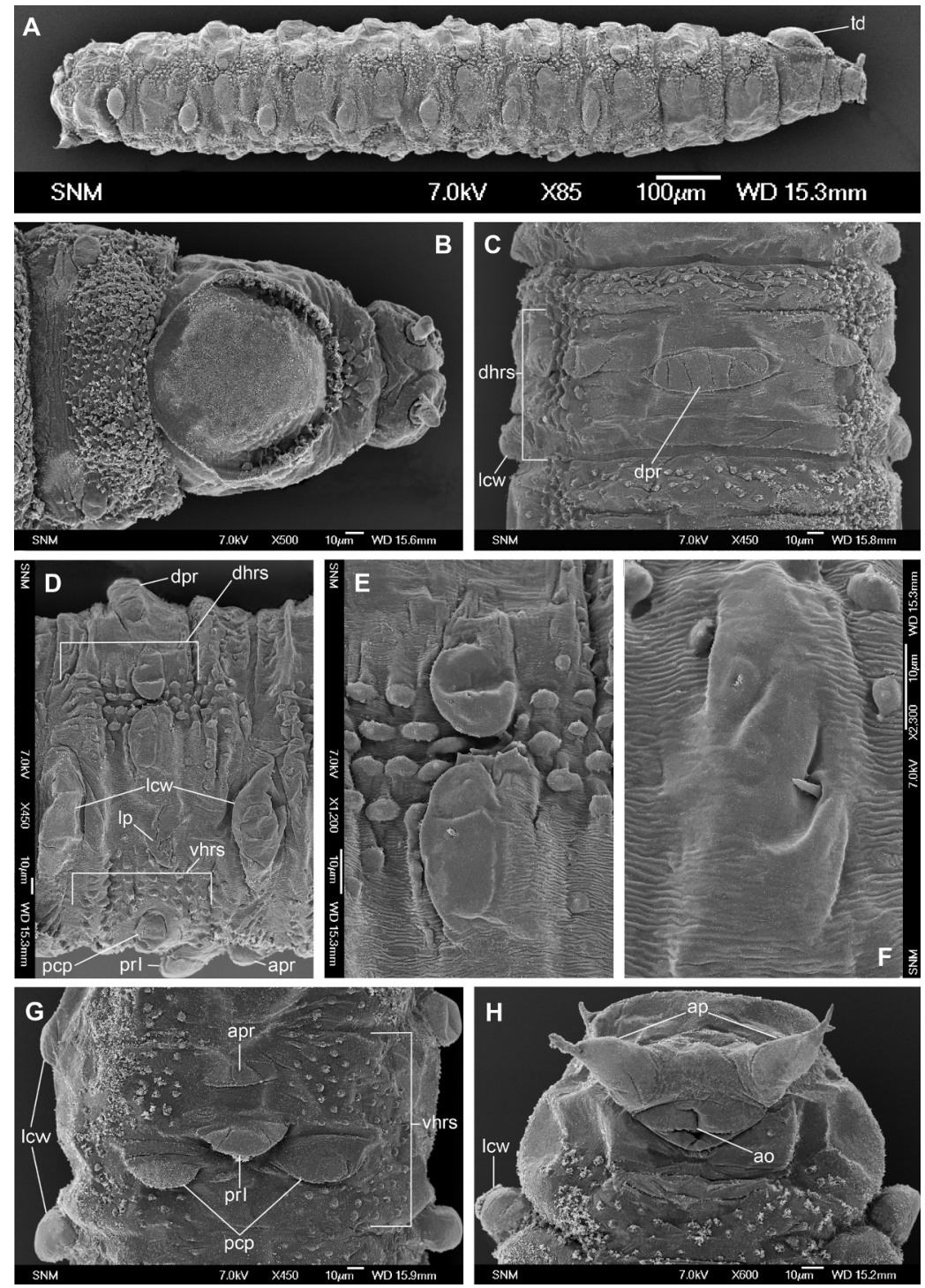

Fig. 3A-H. First instar larva of Taxigramma karakulensis: A - habitus, B - anterior end, dorsal view, $\mathrm{C}-\mathrm{a} 2$, dorsal view, $\mathrm{D}-\mathrm{a} 2$, lateral view, $\mathrm{E}-\mathrm{a}$ 2, dorso-lateral horizontal row of spines, $\mathrm{F}-\mathrm{a}$ 2, lateral papilla, $\mathrm{G}-\mathrm{a} 2$, ventral view, $\mathrm{H}$ - posterior end, ventral view.

a2 - abdominal segment 2, ao - anal opening, ap - anal pads, apr - anterior proleg, dhrs - dorsal horizontal row of spines, dpr - dorsal proleg, lcw - lateral creeping welt, lp - lateral papilla, p1-7 papillae around spiracular field, pcp - post-crevice prolegs, prl - pre-crevice proleg, td - thoracic dome, vcw - ventral creeping welt, vhrs - ventral horizontal row of spines, vp - ventral papillae. 

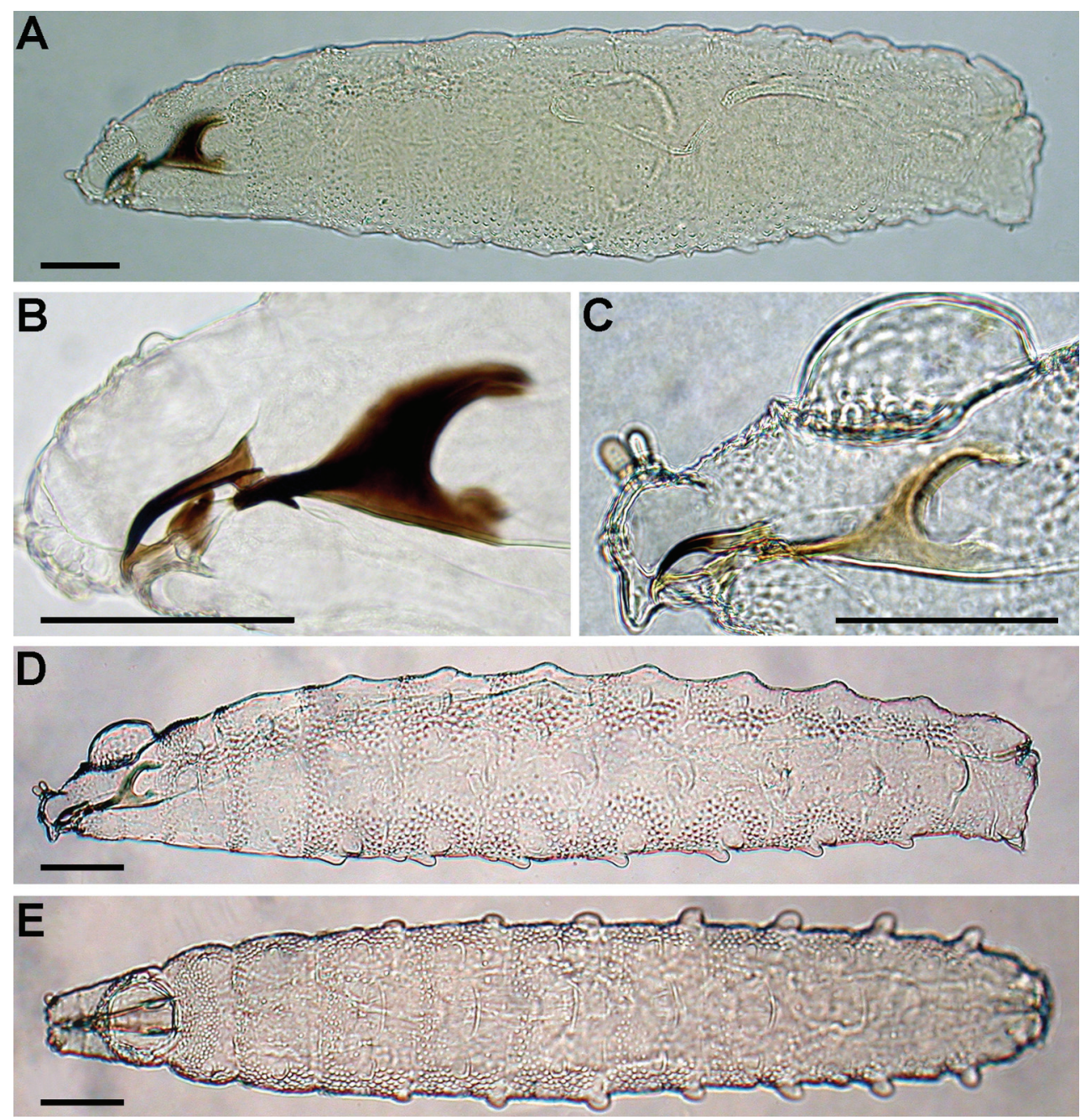

Fig. 4A-E. Cephaloskeleton and habitus of first instar larva of Taxigramma: A - T. albina, habitus, lateral view, B - T. albina, cephaloskeleton, lateral view, C $-T$. karakulensis, cephaloskeleton, lateral view, D - T. karakulensis, habitus, lateral view, E $-T$. karakulensis, habitus, ventral view. Scale bar $=0.1 \mathrm{~mm}$.

Thoracic segments. Anterior spinose bands with from three (lateral surface) to eleven (dorsal surface of segment $\mathrm{t} 2$ ) rows of spines, spines arranged separately, asb on segment $\mathrm{t} 1$ interrupted on dorso-lateral surfaces, asb on dorsal surface of segment $\mathrm{t} 2$ on more than 2/3 length of the segment (Fig. 3B); on dorsal surface of segment t1 large dome-shaped structure (td) present behind asb, horizontal row of spines between asb and td, 
td surrounded by two cuticular folds and anteriorly by semicircular row of spines (Figs 3A, B; 4C-E); lateral surface of segment t1 with group of several papillae; dorso-lateral surface of segments t2-t3 with horizontal row of spines/warts fused with asb, two single bulbous papillae above and below horizontal row of spines; lateral papilla with elongated sensillum.

Abdominal segments. Anterior spinose band complete only on segment a1, on segments a2-a7 interrupted on lateral and ventral surface; asb with from three to five rows of spines, spines arranged separately; psb entirely reduced; lcw large and distended (Figs 3C, D, G, H; 4E); vcw not conspicuous; segments a1-a7 with dhrs on dorso-lateral surface, row fused anteriorly with asb, two large distended papillae above and below dhrs (Fig. 3A, D, E); segments a1-a7 also with vhrs on ventro-lateral surface (Fig. 3D, G); remaining surface of segments a1-a7 with fine cuticular ridges (Fig. 3D-F); lateral papilla with elongated sensillum (Fig. 3F); segments a2-a7 with well-developed system of prolegs, anterior proleg (apr) situated at the antero-ventral margin of each segment, pre-crevice proleg (prl) situated ventrally and immediately anterior to the transverse crevice and centrally on each segment, paired post-crevice prolegs ( $\mathrm{pcp}$ ) situated ventrally and immediately posterior to the transverse crevice and centrally on each segment, dorsal proleg (dpr) present and situated dorso-centrally on segments a1-a6 (Figs 3D, G, 4D).
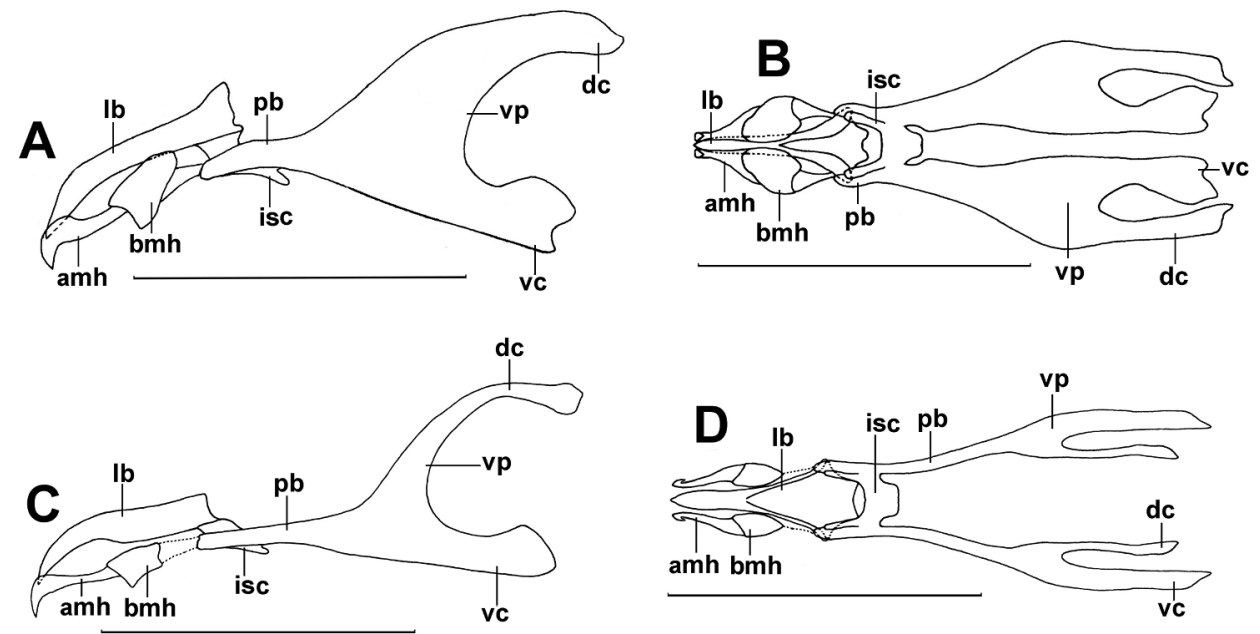

Fig. 5A-D. Cephaloskeleton of first instar larva of Taxigramma: A - T. albina, lateral view, $\mathrm{B}-T$. albina, ventral view, $\mathrm{C}-T$. karakulensis, lateral view, D - T. karakulensis, ventral view. amh - apical part of mouthhook, bmh - basal part of mouthhook, dc - dorsal cornua, isc - intermediate sclerite, $\mathrm{lb}$ - labrum, $\mathrm{pb}$ - parastomal bar, $\mathrm{vc}$ - ventral cornua, $\mathrm{vp}$ - vertical plate. Scale bar $=0.1 \mathrm{~mm}$. 
Anal division. Anterior spinose band developed on ventral and ventro-lateral surfaces, spines sparsely arranged; dorso-lateral surface of ad with horizontal row of cuticular warts; remaining surface of ad with fine cuticular ridges; p1, p3, p5 and p7 clearly visible as fleshy cones with sensillum on top, p2, p4, p6 with sensillum level with surface of ad; multiple rows of sharp spines along ventral edge of spiracular field/cavity, hair-like spines absent; ps in shallow spiracular cavity (slightly subsided spiracular field) and with four small and short peristigmatic tufts; anal pads present as large, elongated and conical fleshy cones, with long apical sensillum (Fig. $3 \mathrm{H}$ ); anal tuft absent.

\section{DISCUSSION}

The morphology of the first instar larvae of T. albina and T. karakulensis fits well within the morphological diversity of the genus Taxigramma as presented by the European species (SzPILA 2010). Larvae of both species possess two character states that are probably autapomorphic for the entire genus, as they have also been described in other species of Taxigramma: 1) parallel ribs on the lateral surfaces of the functional mouth opening, and 2) horizontal rows of spines/warts flanked by two big papillae on the dorso-lateral surface of the thoracic and abdominal segments. However, major morphological differences exist between the larvae of T. albina and T. karakulensis, and they fall within different groupings within the genus. The first instar larva of T. albina is identical with the larvae of T. hilarella (ZETTERStedt, 1844) and T. stictica (MEIGeN, 1830) (genus Hilarella sensu VERVES) and it is very similar to the larva of T. elegantula (ZETTERSTEDT, 1844) (genus Paragusia SCHINER, 1861 sensu VERVES) by virtue of the possession of the following character states: 1) a slender and gradually tapered labrum, 2) a broad basal part of the mouthhooks, 3) a transverse row of papillae on the first thoracic segment, 4) several (10-14) large spines on the ventral surface of the abdominal segments, and 5) lateral papillae on the abdominal segments consisting of two sensilla situated in a shallow pit. The larva of T. karakulensis is more similar to larvae of a group clearly defined by the presence of a unique thoracic dome on the dorsal surface of the first thoracic segment and represented by $T$. heteroneura (MEIGEN, 1830) (Taxigramma sensu VERVES), T. multipunctata (RONDANI, 1859) (Paragusia sensu VeRVES) and T. pseudaperta SÉGUY, 1941 (Paragusia sensu VERVES). Aside from the presence of the 'dome', larvae of this group also possess a group of papillae on the lateral surface of the first thoracic segment and a very broad anterior spinose band on the dorsal surface of the second thoracic segment, which occupies about $2 / 3$ of the length of the segment. Furthermore, the first instar larva of $T$. karakulensis possesses a well-developed system of prolegs similar to that found in T. multipunctata. 
A list of plesiomorphic character states for the first instar larva of calyptrate flies was proposed by SzPILA (2010). The first instar larva of all species of Taxigramma, including the larva of the two species described in the present paper, possess apomorphic states for all these characters in the form of 1) the presence of a large antennal dome, 2) the partial reduction of the antennal basal ring, 3) the lack of oral ridges, 4) the lack of a dorsal bridge, 5) the presence of fine cuticular ridges on the surface of the integument, 6) the strong modification of the spinulation and 7) the lack of hair-like spines around the spiracular field. In terms of the number of derived states, Taxigramma species seem to be among the most evolutionarily advanced taxa of the subfamily Miltogramminae. This conflicts somewhat with the reconstruction by VERVES (1989) of the phylogeny of this group based on adult morphology, where the genus Taxigramma (= Taxigrammatina sensu VERVES) is treated as highly plesiomorphic within the tribe Metopiini. Hopefully, this conflict will be resolved as a result of forthcoming molecular studies of the phylogeny of the entire subfamily.

\section{REFERENCES}

Courtney G.W., Sinclair B.J., Meier R. 2000. Morphology and terminology of Diptera larvae. [In:] PAPP L., DARVAS B. (eds). Contributions to a manual of Palaearctic Diptera (with special reference to flies of economic importance). Science Herald Press, Budapest, pp.: 85-161.

PAPE T. 1987. The Sarcophagidae (Diptera) of Fennoscandia and Denmark. Fauna Entomologica Scandinavica 19: 1-203.

PAPE T. 1996. Catalogue of the Sarcophagidae of the world (Insecta: Diptera). Memoirs of Entomology International 8: 1-558.

Povolný D., Verves Yu.G. 1997. The flesh-flies of central Europe (Insecta, Diptera, Sarcophagidae). Spixiana Supplement 24: 1-260.

Richet R., Verves Yu.G., Whitmore D., PAPE T. 2013. Revision of Taxigramma pseudaperta SÉGUY, 1941 and comparisons with sympatric T. multipunctata (RONDANI, 1859) (Diptera: Sarcophagidae). Zootaxa 2731: 520-532.

RoHDENDORF B.B. 1935. 64 h. Sarcophaginae. [In:] Lindner E. (ed.). Die Fliegen der Palaearktischen Region, 11 [Lieferung 88]: 49-128, 1 pl.

RoHDENDORF B.B. 1967. The directions of historical development of Sarcophagidae (Diptera). Trudy Paleontologicheskogo Instituta Akademii Nauk SSSR 116: 1-92. [In Russian].

SPOFFORD M.G., KURCZEWSKI F.E. 1990. Comparative larvipositional behaviours and cleptoparasitic frequencies of Nearctic species of Miltogrammini (Diptera, Sarcophagidae). Journal of Natural History 24: 731-755.

SzPILA K. 2010. The first instar of European Miltogramminae (Diptera, Sarcophagidae). Wydawnictwo Naukowe UMK, Torun, 272 pp.

SzPIla K., PAPE T. 2005a. The first instar larva of Apodacra pulchra (Diptera: Sarcophagidae, Miltogramminae). Insect Systematics \& Evolution 36: 293-300.

SzPILA K., PAPE T. 2005b. Comparative morphology of the first instar larva of three species of Metopia Meigen (Diptera: Sarcophagidae). Acta Zoologica 86: 119-134.

SzPILA K., PAPE T. 2007. Rediscovery, redescription and reclassification of Beludzhia phylloteliptera (Diptera: Sarcophagidae, Miltogramminae). European Journal of Entomology 104: 119-137. 
SzPILA K., PAPE T. 2008. Morphological diversity of first instar larvae in Miltogramma subgenus Pediasiomyia (Diptera: Sarcophagidae, Miltogramminae). Zoologischer Anzeiger 247: 259-273.

VERVES YU.G. 1989. The phylogenetic systematics of the miltogrammatine flies (Diptera, Sarcophagidae) of the world. Japanese Journal of Medical Science and Biology 42: 111-126.

Received: 10 October 2013

Accepted: 12 November 2013 